\title{
BMJ Open International Study of Definitions of English-Language Terms for Suicidal Behaviours: protocol of an opinion survey
}

\author{
Benjamin Goodfellow, ${ }^{\oplus 1,2}$ Kairi Kõlves, ${ }^{\oplus 1}$ Diego De Leo, ${ }^{1}$ Morton Silverman, ${ }^{3}$ \\ Alan Berman, ${ }^{4}$ John Mann, ${ }^{5}$ Ella Arensman, ${ }^{6}$ Keith Hawton, ${ }^{\circ 7}$ Michael Phillips, ${ }^{8}$ \\ Lakshmi Vijayakumar $^{9}$
}

To cite: Goodfellow B, Kõlves K, De Leo D, et al. International Study of Definitions of EnglishLanguage Terms for Suicidal Behaviours: protocol of an opinion survey. BMJ Open 2019;9:e025770. doi:10.1136/ bmjopen-2018-025770

- Prepublication history and additional material for this paper are available online. To view these files, please visit the journal online (http://dx.doi. org/10.1136/bmjopen-2018025770).

Received 28 August 2018 Revised 12 June 2019 Accepted 13 June 2019

Check for updates

(C) Author(s) (or their employer(s)) 2019. Re-use permitted under CC BY-NC. No commercial re-use. See rights and permissions. Published by BMJ.

For numbered affiliations see end of article.

Correspondence to Dr Benjamin Goodfellow; b.goodfellow@chs.nc

\section{ABSTRACT}

Introduction The objective of present paper is to outline the methodology of the International Study of Definitions of English-Language Terms for Suicidal Behaviours (ISDELTSB). The aim of the study is to survey existing English language terms and definitions used around the world for suicidal behaviour.

Methods and analysis The ISDELTSB is a worldwide survey based on one 'designated expert' per each WHOregistered country. 'Experts' were contacted through the International Association for Suicide Prevention (IASP), the World Psychiatric Association and the World Organization of Family Doctors. Each individual was sent an invitation to participate and a link to an online questionnaire. A comparison sample was created by inviting all IASP members to respond to the questionnaire. The questionnaire was designed to assess respondents' preferences about a particular set of terms and definitions by using the four major criteria of the definition of suicide identified in the literature (outcome, intent, knowledge and agency). The questionnaire used a multiple-choice question format. Participants were asked to choose one term in the list for each of the proposed definitions. Statements and definitions in the questionnaire were elaborated using the four main features of the definition of suicide, starting by the definitions and terms for which there is already a certain degree of consensus and then progressing to definitions and terms less agreed on. Ethics and dissemination The study protocol obtained approval of Griffith University's Ethics Committee (ethics reference number 2017/601) and in accordance with the Australian National Statement on Ethical Conduct in Human Research. Respondents are asked if they accept to be personally acknowledged in any output originating from this study, and if so to provide their full name, title and affiliations. If respondents do not accept, they are informed that the conduct of this research respects Griffith University's Privacy Plan and that identified personal information is confidential and that anonymity will at all times be safeguarded. As detailed in the questionnaire cover letter, by answering the online or paper version of the questionnaire, respondents express their consent to participate. Dissemination of results will be done through a peer-reviewed journal article publication. This study aims to map the international use of definitions and terms for
Strengths and limitations of this study

- This study is the first of its kind, surveying existing definitions and terms used around the world for suicidal behaviour.

- It is authored by a special interest group part of an international organisation (International Association for Suicide Prevention).

It is focused on English language.

It is partly based on self-defined expertise.

suicidal behaviour and ideation and favour the future use of an internationally shared set of terms and definitions. This will hopefully avoid undue duplication of efforts and reliably permit meta-analysis of data produced in different countries.

\section{INTRODUCTION AND RATIONALE}

Suicidal behaviour represents a significant global health burden. Research and prevention efforts have only recently started to counteract the phenomenon. $\mathrm{WHO}^{1}$ has recommended that suicide prevention should become a priority for national health stakeholders and governments, and the United Nations have included the reduction of suicide mortality as one of the key indicators for achieving the Sustainable Development Goals by $2030 .^{2}$ Despite the appearance of suicidology as a specific discipline less than 70 years ago, ${ }^{3}$ and the growing body of knowledge arising from it, the exchange of information between different professionals in the area still poses serious problems. Indeed, definitions and terms related to suicidal ideation and behaviour vary considerably around the world, as demographers, statisticians, coroners, clinicians, researchers, public health experts, and so on, in different countries (and often within the same country) use their 
own terminology and definitions. For this reason, in the field of research, it is difficult to compare or combine efforts from different investigators. This would permit appropriate evaluations or reaching the statistical power that for a rare phenomenon like suicide remains one of the major obstacles to the generalisation of results. Thus, comparing or assembling research data through meta-analytic procedures continues to be a challenging task because of the difficulty in overlapping categories of suicidal behaviours used by different researchers. These categories are often idiosyncratically and sometimes imprecisely defined. Among the authors that have solicited interventions in this problematic area, Silverman and $\mathrm{De} \mathrm{Leo}^{4}$ argued for the establishment of a shared set of terms and definitions, that is, a common nomenclature usable worldwide that would enable researchers to compare their work and avoid unnecessary duplication of efforts. A common language would improve communication between professionals and, most importantly, would enable the elaboration of common criteria that can be used worldwide to classify deaths as suicide, thus increasing the validity and reliability of mortality statistics. In turn, this would help stakeholders and government agencies to wisely allocate available resources and, thus, promote more effective suicide prevention practices.

A systematic literature review of terms, definitions, nomenclatures and classifications for suicidal ideation and behaviours ${ }^{5-7}$ revealed a heterogeneous and sometimes contradictory landscape reminding us that we are presently far away from reaching international consensus in these areas. Moreover, the review was restricted to the English language literature: a study of terms and definitions in other languages would probably reveal an even more challenging scenario. However, the literature evidences the existence of sufficient agreement around the main criteria characterising fatal suicidal behaviour (ie, 'suicide'): agency (self-inflicted or other inflicted), knowledge (of the consequences of the act), intent and outcome. ${ }^{6}$

The reviews mentioned before ${ }^{5-7}$ found that today it would not be possible to elaborate and standardise a universal set of terms and definitions describing the whole range of suicidal ideation and behaviours. Apparently, there are two main reasons for this. First, the level of international consensus is too low, especially for suicidal ideation and non-fatal suicidal behaviours. Second, the existing literature on the subject is quite limited. If terms and definitions were to be widely accepted and used by clinicians and researchers around the world, there would need to be a high level of agreement among potential users of these terms and definitions.

\section{THE INTERNATIONAL STUDY OF DEFINITIONS OF ENGLISH- LANGUAGE TERMS FOR SUICIDAL BEHAVIOURS}

The idea of an international study of definitions and terms for suicidal behaviours was developed in 2013 under the initiative of one of the authors (DDL) and became the subject of a $\mathrm{PhD}$ thesis by another of the authors (BG). A systematic review of the literature on nomenclatures, definitions and classifications for suicidal ideation and behaviours was undertaken to provide the necessary background for the study. The outputs of this review $^{6}$ were then used to create a questionnaire that would enable the assessment of the most widely used terms and definitions around the world which is the final aim of the research. The aim of the current paper is to describe the methodology of the International Study of Definitions of English-Language Terms for Suicidal Behaviours (ISDELTSB), that is, the selection of participants, the questionnaire design and validation process, and the planned analysis of results.

\section{PARTICIPANTS}

In the ISDELTSB, targeted respondents are designated experts, with one 'expert' each representing one participating country. The method of recruitment of these 'experts' uses a network provided by four main institutions: the International Association for Suicide Prevention (IASP), the World Psychiatric Association (WPA), the World Organization of Family Doctors (WONCA) and the Australian Institute for Suicide Research and Prevention (AISRAP). Inclusion criteria are to be designated by one of the organisations just cited, to be a professional working in the field of suicide research or prevention, to be experienced enough to have good knowledge of the terms and definitions used to describe suicidal behaviour in corresponding country such as determined by the organisation or professional recommending that 'expert', and to feel confident in answering the survey questionnaire. Only one expert per country is included. There are no exclusion criteria based on professional or academic background, and participants are excluded if they do not feel confident in answering the questionnaire. The recruitment methodology was standardised.

Constitutionally, IASP includes a Council of National Representatives, which currently has representatives from 62 countries. A personal invitation was sent by email to all IASP national representatives. This email includes a link to the online study questionnaire. The invitation letter asks the representative to provide the name of an appropriate respondent if the recipient does not feel confident enough in answering the questionnaire. Indeed, despite some significant level of expertise, IASP national representatives might not necessarily be aware of the most used terms in their country to define suicidal behaviour. In order to increase the number of designated 'experts', an explanatory email was sent to the WPA and the WONCA. This email describes the aim of the study and asked for contact information for relevant 'experts' from countries not yet having an IASP designated 'expert'. Once identified, these 'experts' receive an email invitation similar to the one sent to IASP national representatives. If IASP, WPA and WONCA designated 'experts' do not answer within a week, a second invitation is then sent, and then a 


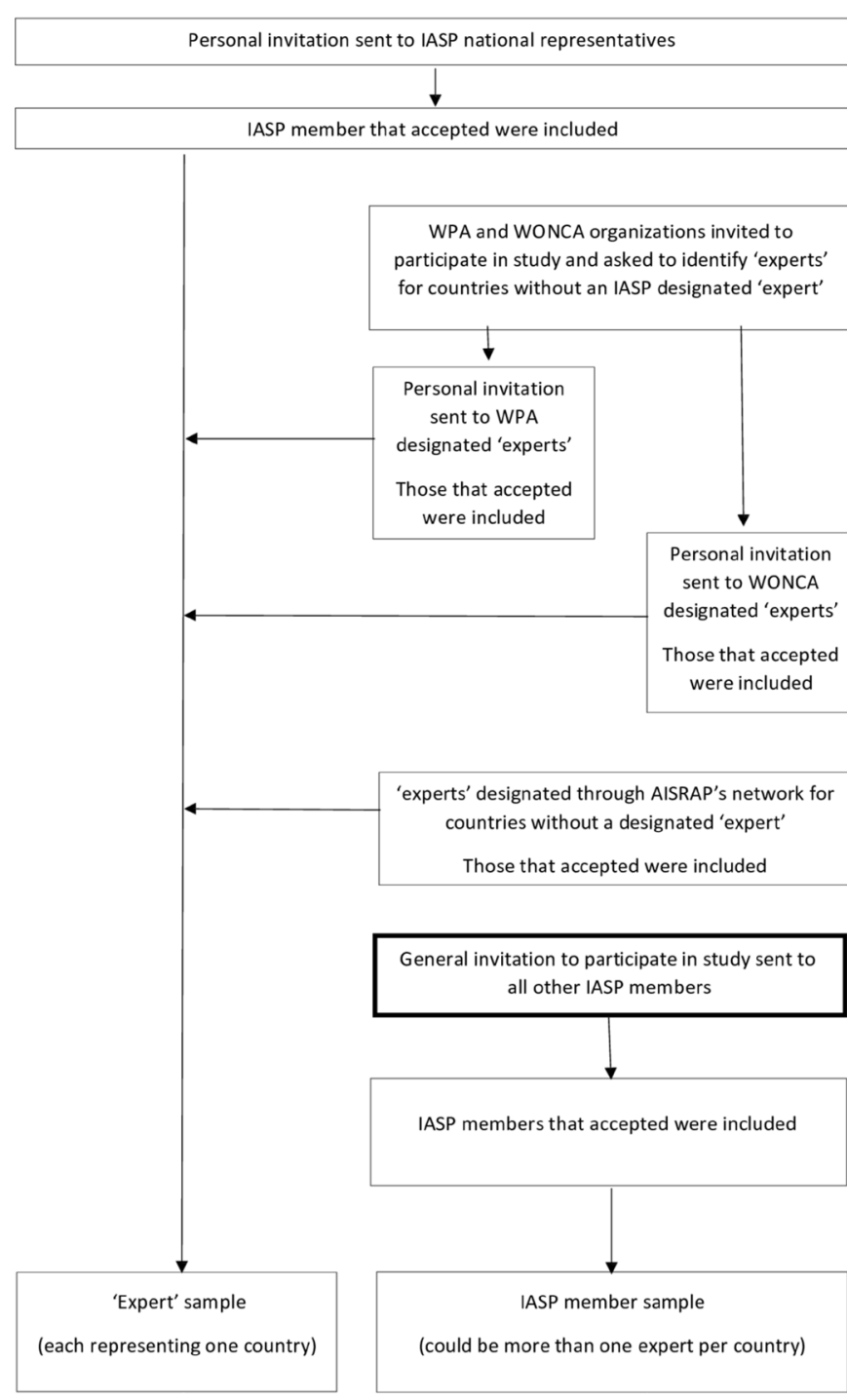

Figure 1 Flow chart of inclusion of International Study of Definitions of English-Language Terms for Suicidal Behaviours participants. AISRAP, Australian Institute for Suicide Research and Prevention; IASP, International Association for Suicide Prevention; WONCA, World Organization of Family Doctors; WPA, World Psychiatric Association.

third after another week. If no response is obtained after three email invitations, the 'expert' is excluded. Using the same method, more experts could be identified through AISRAP's international network for countries which do not have a designated 'expert'. If no 'expert' can be identified after all, the country cannot be included in the 'expert' sample. Refer to the flow chart in figure 1.

In a second phase of the study, a general invitation was sent to all IASP members except national representatives, thus building a separate sample of participants to enable comparisons between the two groups of recruits.

\section{QUESTIONNAIRE}

The English-language questionnaire was distributed to respondents using Qualtrics software. A paper version of the questionnaire was also prepared for respondents with no Internet access or those preferring a paper version. The latter is included as online supplementary file.

An introduction to the questionnaire details the framework and rationale of the study, the level of expertise required, expected questionnaire completion time and ethical and confidentiality considerations. This section clearly explains that the answers should represent the opinion of the majority of professionals who deal with suicide in the country, rather than being based solely on the opinions of the respondent.

The multiple-choice format to the questionnaire will result in percentages for each option that can be used to assess the level of agreement about specific terms and definitions.

The questionnaire is divided into four main parts. The first part covers the definition of suicide. The second addresses different forms of fatal and non-fatal suicidal behaviours and self-harm. The third part focuses on suicidal ideation, and the fourth on distinguishing between ideation and behaviour.

\section{Suicide}

The questionnaire separately assesses opinions regarding each of the four main features of the definition of suicide (ie, agency, knowledge, intent and outcome). A recent review ${ }^{6}$ highlighted the importance of these features in the definition of suicide. Several statements were created, providing possible alternatives for each of the four main features. For instance, the statement on outcome read as follows:

Please choose one single statement to complete the sentence: Suicide is an act that

- Necessarily leads to death.

- May result in survival.

Respondents had to choose a single answer to complete the sentences related to 'outcome' and 'agency'. In the case of 'intent' and 'knowledge', several statements are proposed to respondents, who have to choose if they agreed or disagreed with each of the statements, as illustrated in table 1 for 'intent'.

Respondents have the opportunity to comment on their choices and provide alternative terms for suicide if they think that this term is not appropriate.

\section{Other types of suicidal behaviour and self-harm}

The three following sections were built using the 'clinical' vignette method. This particular section focuses on self-harm behaviours with or without suicidal intent where the person either dies or survives. The vignettes do not present real-life situations but rather described basic behaviours corresponding to the definitions found in the review of the literature. ${ }^{6}$ For Instance, question 10 read as follows:

Please choose one single statement to complete the sentences

10. In your country, when professionals (eg, clinicians, researchers) talk about other types of suicidal behaviour than suicide, the most common understanding is that 
Table 1 Statements regarding intent in the International Study of Definitions of English-Language Terms for Suicidal Behaviours questionnaire: 'please tick Yes if you agree with statement in table, or No if you don't'

\begin{tabular}{lll}
\hline Statements & Yes & No \\
\hline $\begin{array}{l}\text { Suicide is an act that can only be done } \\
\text { with an intent to die }\end{array}$ & 0 & 0 \\
$\begin{array}{l}\text { Suicide is an act that may be done with an } \\
\text { intent other than an explicit intent to die }\end{array}$ & 0 \\
$\begin{array}{l}\text { Suicide is an act that may be done with an } \\
\text { ambiguous or unclear intent }\end{array}$ & 0 \\
$\begin{array}{l}\text { Suicide is an act that may be done with an } \\
\text { intent to take the risk of dying }\end{array}$ & 0 \\
$\begin{array}{l}\text { Suicide is an act that may be done without } \\
\text { explicit intent to die' }\end{array}$ & 0 & 0 \\
\hline
\end{tabular}

when a person harms himself or herself, with the intention to die, and survives, his or her act is:

After reading each vignette, respondents have to choose a single option from a list to name the described behaviour. For instance, in case of question 10:

- A suicide attempt

- Parasuicide

- Self-harm

- Deliberate self-harm

- Non-suicidal self-injury

- Self-mutilation

- Non-fatal suicidal behaviour

- Self-directed violence

- Self-injurious behaviour (including self-poisoning/ overdosing with medication)

These terms were found by reviewing the literature on nomenclatures, definitions and classifications. ${ }^{5-7}$ There is no right or wrong answer. However, results of our reviews indicated that there might be a high level of consensus for some particular case descriptions; for instance, in question 10, one might expect a higher number of answers indicating 'A suicide attempt'.

\section{Suicidal ideation}

This section assesses definitions of different degrees or patterns of suicidal ideation, with or without suicidal intent, as in question 16:

16. In your country, when professionals (eg, clinicians, researchers) talk about suicidal ideation, the most common understanding is that when someone who occasionally thinks of suicide when confronted to distress, this person has:

- A normal pattern of thinking

- Suicidal ideation

- Passive suicidal ideation

- Active suicidal ideation

- Death wishes

- Reactive suicide ideation

\section{Suicidal ideation or behaviour}

This section assesses the boundaries between suicidal ideation and behaviour and proposed vignettes describing situations that could be defined as either one or the other. These situations were chosen because they are often referred to in the literature. For instance, for the following example, one might expect the answer 'Is engaging in preparatory suicidal behaviour':

In your country, when professionals (eg, clinicians, researchers) talk about suicidal behaviour or ideation, the most common understanding is that when someone prepares a suicidal act (eg, assembles pills, buys a gun, attaches a rope, visits a bridge), but does not initiate it and thus does not sustain any injuries, this person:

- Is engaging in suicidal behaviour

- Is experiencing suicidal ideation

- Is experiencing passive suicidal ideation

- Is experiencing active suicidal ideation

- Has made a suicide attempt

- Has made a suicide threat

- Has made a suicide communication

- Has made a suicide plan

- Is engaging in preparatory suicidal behaviour

- Has made an interrupted suicide attempt

- Has made an aborted suicide attempt

This area of investigation is very controversial and complicated, and the level of consensus among international experts around this particular question is expected to be quite low.

The construction of the questionnaire thus followed a progression from terms and definitions that were quite shared and agreed on in the literature to the ones that are less agreed on and more complex. ${ }^{5-7}$

\section{Questionnaire validation process}

The study questionnaire was assessed regarding content validity. The first version of the questionnaire was reviewed by the members of the IASP Taskforce on Nomenclature and Classifications, namely, E. Arensman, A. Berman, K. Hawton, J. Mann, M. Philips, M. Silverman and L. Vijayakumar, who coauthored this article. The questionnaire was modified after the input of each member. Feedback was mainly centred on the following issues: phrasing and logical layout of questions, terminology, relationship with evidence, field work, cultural context, usefulness of certain questions with regards to the logic of questionnaire, issues of understandability and clarification of ambiguous terms.

The modified version was then sent out to a sample of experts (IASP National Representatives) in four culturally different countries, namely Pakistan, Uganda, Portugal and Tonga. The questionnaire was found to be acceptable and understandable by the 'experts' of these countries and considered ready to be sent out to all other countries.

\section{PATIENT AND PUBLIC INVOLVEMENT STATEMENT}

No patients or public were involved in the design of this study. 


\section{Analysis of results}

Expected outcomes are percentages of agreement with each answer. Differences of agreement between 'experts' and IASP members will be analysed using ORs or Fisher exact tests if expected numbers are less than 6 . In order to further assess agreement or disagreement, both these samples will be blended together and levels of agreement will again be analysed between respondents from high-income versus low-income and middle-income countries, countries in which English is the main or one of the main languages spoken versus countries where it is not, between occupation groups, and between professional background groups. Two of the authors (BG and KK) will analyse the data, and results will be discussed among the Taskforce.

Responses attaining a high level of agreement would be candidates for integrating an agreed-upon nomenclature. Those with lower levels of agreement could be discussed in the light of the reasons for disagreement (ie, which groups disagree, why they disagree and what are the comments of respondents). The aim of the study is to identify the minimum number of items on which international professionals could be said to reasonably agree on, and discuss opportunities for developing further consensus.

\section{LIMITATIONS}

The study is being conducted in the English language only. This will limit the reach of the nomenclature originating from the study, and will render its cross-cultural validity debatable. On the other hand, the methodological implications of conducting a multilingual study would pose serious problems with regards to translation and back translation. This study was designed to be the first of its kind, that is, a first attempt to survey the filed internationally and it was decided to conduct it in English. A future experiment should assemble a wider sample of professionals around the world.

The criteria used to recruit 'experts' rely on an appreciation by the institution to which the 'expert' belongs and the confidence of the participant in answering to the study as a representative of his or her country. No other objective criteria were established by the research team, and this could lead to question the expertise of participants in the 'expert' sample. For this reason, single quotation marks were used for the word 'expert' in the context of the ISDELTSB. Indeed, confronted with the scarcity of literature on the subject of definitions and terms, ${ }^{5-7}$ it is expected that great difficulties will be faced when attempting to recruit participants with a sufficient level of expertise for such a specialised field of knowledge. Setting too high a threshold may result in extremely low participation rate. For this reason, the recruitment method in this sample used a personal approach by direct email contact between the investigator and the participant, which is probably more stimulating than a general invitation and could result in a higher participation rate in this sample. This in turn could result in a wider range of countries being represented. On the other hand, in spite of the varying size of countries around the world, only one 'expert' for each country is appointed, which could bias results towards countries with smaller population by not recruiting more 'experts' for more populated countries. Based on the results of the literature review, it is expected that many knowledgeable respondents will be found in high-income countries, especially the USA. The proposed methodology was thought to encourage wider representativity and relatively more focus on low-income and middle-income countries. Also, the recruitment methodology was standardised. Nevertheless, further research in the field could aim at more practical approaches to testing classifications in real-life situations by field professionals which could potentially raise more interest and the participation rate.

IASP and AISRAP are multidisciplinary institutions including psychologists, psychiatrists and sociologists among other disciplines. On the other hand, WPA and WONCA are medical associations, which could bias results towards medically used definitions of suicidal behaviours. However, WPA and WONCA can be counted among the very few organisations that could claim some competence in the field of suicide prevention and at the same time tend to have worldwide representativity. The opinions expressed by the designated 'experts' will be compared with those of IASP members participating in the effort. In a number of cases, this will allow for a check of the consistency of the opinions expressed by the designated 'experts'. Analyses will also be performed with regards to professional background, which will control for any disciplinary bias.

\section{CONCLUSION}

This paper outlines the main features of the ISDELTSB. The study is based on a review of the literature on nomenclatures, definitions, terms and classifications for suicidal behaviour that found a confusing landscape and poor agreement among authors who publish in English. The study questionnaire was developed on the basis of the four main criteria of the definition of suicidal behaviour: outcome, intent, knowledge (of the consequences of the act) and agency (self-inflicted or other inflicted). Respondents are encouraged to take clear-cut decisions with limited answer options. The results of this survey will provide several indications, including the state of the art on prevailing terms and definitions. This would help in elaborating an internationally applicable nomenclature for suicidal ideation and behaviour. The next step could be to elaborate a classification of suicidal behaviour. A better knowledge of the international scenario may help to reduce confusion in the field of suicidology and progress towards a shared understanding of suicidal behaviour.

Author affiliations

${ }^{1}$ Australian Institute of Suicide Research and Prevention, Griffith University, Brisbane, Queensland, Australia 
${ }^{2}$ Department of Psychiatry, Centre Hospitalier Albert Bousquet, Nouméa, New Caledonia

${ }^{3}$ Department of Psychiatry, Medical College of Wisconsin, Milwaukee, Wisconsin, USA

${ }^{4}$ Department of Psychiatry and Behavioral Sciences, Johns Hopkins School of Medicine, Baltimore, Maryland, USA

${ }^{5}$ Department of Neuroscience, Columbia University, New York, USA ${ }^{6}$ National Suicide Research Foundation, School of Public Health, Cork, Ireland

${ }^{7}$ Psychiatry, Centre for Suicide Research, Oxford University, Oxford, UK

${ }^{8}$ Suicide Research and Prevention Center, Shanghai Mental Health Center, Shanghai, China

${ }^{9}$ Department of Psychiatry, Voluntary Heath Services, Chennai, India

Acknowledgements The authors would like to thank IASP Administrative Officers, Wendy Orchard and Wendy Cliff; Roy Abraham Kallivayalil, Secretary General at the WPA, as well as the WPA team; Chris Dowrick, Chair of Working Party for Mental Health at WONCA, as well as the WONCA team, for their assistance in distributing the questionnaire. We would also like to acknowledge Mrs Daphne Goodfellow for her help in language editing.

Contributors BG helped design the study, designed the questionnaire, drafted and wrote the manuscript. KK helped design the study, helped design and critically reviewed the questionnaire, and critically reviewed the manuscript. DDL originated the study idea and design, helped design and critically reviewed the questionnaire, and critically reviewed the manuscript. MS, AB, JM, EA, KH, MP and LV reviewed the questionnaire and critically reviewed the manuscript.

Funding The authors have not declared a specific grant for this research from any funding agency in the public, commercial or not-for-profit sectors.

Competing interests None declared.
Patient consent for publication Not required.

Provenance and peer review Not commissioned; externally peer reviewed.

Open access This is an open access article distributed in accordance with the Creative Commons Attribution Non Commercial (CC BY-NC 4.0) license, which permits others to distribute, remix, adapt, build upon this work non-commercially, and license their derivative works on different terms, provided the original work is properly cited, appropriate credit is given, any changes made indicated, and the use is non-commercial. See: http://creativecommons.org/licenses/by-nc/4.0/.

\section{REFERENCES}

1. World Health Organization. Preventing suicide: a global imperative. Geneva: World Health Organization, 2014.

2. United Nations, Sustainable Development Goal 3. Sustainable Development Knowledge Platform. 2016 https://sustainabledevel opment.un.org/sdg3 (Cited Mar 2019).

3. Maris RW. et a/The evolution of Suicidology. In: Leenaars AA, Berman AL, Cantor P, Litman R E, . eds. Suicidology: essays in honor of Edwin S Shneidman: Jason Aronson, 1993.

4. Silverman MM, De Leo D. Why there is a need for an international nomenclature and classification system for suicide. Crisis 2016;37:83-7.

5. Goodfellow B, Kõlves K, de Leo D. Contemporary nomenclatures of suicidal behaviors: a systematic literature review. Suicide and LifeThreatening Behavior 2018;48:353-66.

6. Goodfellow B, Kõlves K, de Leo D. Contemporary definitions of suicidal behavior: a systematic literature review. Suicide Life Threat Behav 2019;49:353-66.

7. Goodfellow B, Kõlves K, de Leo D. Contemporary nomenclatures of suicidal behaviors: a systematic literature review. Crisis 2018;48. 